\title{
A Simple Dietary Intervention in the School Setting Decreased Incidence of Overweight in Children
}

\author{
Rebecca Muckelbauer $^{\mathrm{a}} \quad$ Lars Libuda $^{\mathrm{a}}$ Kerstin Clausen ${ }^{\mathrm{a}} \quad$ Thomas Reinehr $^{\mathrm{b}}$ Mathilde Kersting ${ }^{\mathrm{a}}$ \\ ${ }^{a}$ Research Institute of Child Nutrition Dortmund, \\ ${ }^{\mathrm{b}}$ Department of Pediatric Nutrion Medicine, Vestic Children's Hospital, University of Witten/Herdecke, Germany
}

\section{Key Words}

Randomized controlled trial · Environmental intervention - Educational intervention . Childhood overweight

\section{Summary}

Objective: The study analyzed the effect of a combined environmental and educational intervention solely promoting water consumption on the incidence of overweight among school children. Methods: 2,950 second and third graders of 32 elementary schools in socially deprived neighborhoods of two German cities participated in a randomized controlled intervention trial (August 2006-June 2007). In intervention schools ( $N=17$ ), water fountains were installed, each child received a water bottle, and teachers performed classroom lessons to promote water consumption. Control schools $(N=15)$ did not receive any intervention. Body heights and weights were measured at baseline and follow-up to assess the incidence and remission of overweight and obesity during follow-up. The water flow of the fountains was measured regularly during follow-up. Children's beverage consumption was self-reported in 24-hour recall questionnaires before and after intervention. Results: After the intervention, the incidence of overweight was significantly lower in the intervention group $(3.8 \%)$ than in the control group $(6.0 \%, p=0.018)$. Remission of overweight and obesity did not differ between the groups. Measured water flow of the fountains indicated a sustained use. Conclusion: A simple dietary intervention with the sole focus on the promotion of drinking water effectively reduced the incidence of overweight among school children.

\section{Introduction}

The prevention of overweight and obesity in children is one of the major challenges for medicine and public health today [1]. A recent Cochrane Review [2] was not able to identify one particular intervention that prevents obesity in children but designated programs as more promising that consider environmental modifications in addition to individual behavior changes. Prompted by the beneficial effect on weight status demonstrated in two recent smaller intervention trials focusing on decreasing caloric soft drink consumption [3, 4], we evolved an intervention program for school children with the sole focus on the promotion of water consumption. Additionally to an educational intervention, environmental modifications were implemented in the school setting for facilitating the access to drinking water and increasing the attractiveness of water consumption. We conducted a large randomized controlled trial with elementary school children in deprived urban neighborhoods and found a reduced risk for the prevalence of overweight after the intervention [5]. In the present secondary analysis, we tested whether the incidence and remission of overweight and obesity was lower in the intervention group (IG) than in the control group (CG) as a consequence of the promotion of drinking water.

\section{Participants and Methods}

Methods and design of the randomized controlled cluster trial have been described in detail elsewhere [5]. The study population comprised children attending the second and third grades of elementary schools in socially deprived neighborhoods of two cities in Germany, Dortmund and Essen. The neighborhoods were defined by socio-demographic criteria as provided by the local public authorities for the city districts [6]. Randomization of the intervention was performed at city level with Dortmund as IG and Essen as CG. Of 81 eligible schools in the defined districts, 40

\begin{tabular}{ll}
\hline KARGER & $\oplus$ 2009 S. Karger GmbH, Freiburg \\
Fax +497614520714 & Accessible online at: \\
Information@Karger.de & www.karger.com/ofa \\
www.karger.com &
\end{tabular}


Table 1. Baseline characteristics of participants and schools of the intervention group (IG) and control group $(\mathrm{CG})$

\begin{tabular}{|c|c|c|c|c|c|c|}
\hline \multirow[t]{2}{*}{ Characteristic } & \multicolumn{2}{|l|}{ T0 } & \multirow[t]{2}{*}{$\mathrm{p}$ value $\mathrm{a}^{\mathrm{a}}$} & \multicolumn{2}{|l|}{$\mathrm{T} 1$} & \multirow[t]{2}{*}{$p$ value $^{a}$} \\
\hline & IG $(\mathrm{N}=1,641)$ & $\mathrm{CG}(\mathrm{N}=1,309)$ & & $\mathrm{IG}(\mathrm{N}=1,641)$ & $\mathrm{CG}(\mathrm{N}=1,309)$ & \\
\hline Age, mean $\pm \mathrm{SD}$, years & $8.26 \pm 0.73$ & $8.34 \pm 0.76$ & 0.009 & $8.94 \pm 0.73$ & $9.03 \pm 0.76$ & 0.003 \\
\hline $\mathrm{BMI}$, mean $\pm \mathrm{SD}, \mathrm{kg} / \mathrm{m}^{2}$ & $17.11 \pm 2.78$ & $17.39 \pm 3.10$ & 0.050 & $17.50 \pm 2.97$ & $17.80 \pm 3.26$ & 0.037 \\
\hline BMI-SDS, mean \pm SD & $0.23 \pm 1.06$ & $0.30 \pm 1.13$ & 0.108 & $0.23 \pm 1.07$ & $0.31 \pm 1.13$ & 0.087 \\
\hline Body weight status ${ }^{\mathrm{b}}$ & & & 0.138 & & & 0.045 \\
\hline Obese, \% (n) & $6.2(102)$ & $8.4(110)$ & & $6.1(100)$ & $8.0(105)$ & \\
\hline Overweight, \% (n) & $17.2(282)$ & $17.5(229)$ & & $17.4(285)$ & $19.8(259)$ & \\
\hline Normal weight, \% (n) & $68.7(1,128)$ & $66.2(897)$ & & $69.8(1,145)$ & $65.8(861)$ & \\
\hline Underweight, \% (n) & $7.9(129)$ & $7.5(98)$ & & $6.8(111)$ & $6.4(84)$ & \\
\hline
\end{tabular}

${ }^{\mathrm{a}} \mathrm{p}$ value obtained using chi-square test or Wilcoxon rank sum test for group differences.

${ }^{\mathrm{b}}$ According to the International Obesity Taskforce [9] and Cole et al. [10]. schools (IG: $\mathrm{N}=20, \mathrm{CG}: \mathrm{N}=20$ ) were randomly selected. Out of these schools, 1 intervention school did not meet technical requirements for the fountain installation, 6 schools declined participation, and 1 control school withdrew participation during follow-up by reason of limited resources. Finally, 32 schools (IG: N = 17, CG: N = 15) finished the followup period. Before intervention, we obtained written parental consent for $3,220(84 \%)$ second and third graders attending the participating schools. Out of the 3,190 participants screened at baseline, 2,950 (92\%) children (IG: 95\%, CG: 89\%) were also measured at follow-up and considered for analysis. Drop-outs during follow-up occurred mainly due to moving the class $(n=119)$ and 1 school's withdrawal of participation $(n=89)$.

The intervention lasted 1 school year from August 2006 to follow-up measurements in June 2007 (250 days). As an environmental modification, water fountains, which provided cooled and optionally carbonated water for free, were installed in the intervention schools, and each child received an appealing plastic water bottle. The educational intervention consisted of four 45-min classroom lessons based on the theory of planned behavior $[7,8]$. Teachers received a booklet with the prepared curriculum including necessary material and performed the lessons at the beginning of the study. The CG did not receive any intervention.

Body weights and heights were measured at baseline and follow-up by 2 trained health professionals. Overweight (exclusive obesity) and obesity were determined according to the standard of the International Obesity Taskforce [9] and underweight by a definition for international use according to an adult cut-off of $18.5 \mathrm{~kg} / \mathrm{m}^{2}$ [10]. The incidence rate of overweight during the intervention was defined as the number of newly diagnosed overweight children at follow-up in relation to the number of nonoverweight children (normal weight and underweight) at baseline. The remission rate of overweight was defined as the number of participants that were no longer overweight at follow-up divided by the number of all overweight (excluding obese) children at baseline. The incidence rate of obesity was the number of newly diagnosed obese children divided by the number of overweight children at baseline. Accordingly, remission rate of obesity was calculated on the basis of all obese children at baseline. BMI was converted into sex- and age-independent, continuous standard deviation scores (BMI-SDS) based on German reference percentiles [11].

A secondary outcome was the beverage consumption of the participants. Two types of data were used: i) repeated assessment of the water flow of the fountains in the intervention schools ( 7 times with a mean interval of 43 days); ii) change in children's beverage consumption (mean number of glasses/day in 7 beverage categories) which was self-reported in a 24-h recall questionnaire administered in the classroom at baseline and follow-up. The picture-based questionnaire was approved and adapted for the relevant age group of children by a pre-test in 1 elementary school. A questionnaire was considered as plausible if a total daily beverage consumption $>0$ glasses and $\leq 20$ glasses was indicated. Out of 2,950 participants, 1,987 (67\%) children (IG: $\mathrm{n}=1,070, \mathrm{CG}: \mathrm{n}=917)$ had plau- sible questionnaires at both baseline and follow-up. Methods and results of process evaluation are described elsewhere [5].

Baseline comparability between the groups was assessed using chisquare test or Wilcoxon rank sum test where appropriate. The intervention effect was statistically analyzed by comparing the incidence and remission of overweight and obesity between IG and CG using chi-square test. For the evaluation of the water flow during the follow-up period, Pearson correlation analysis was used. Changes in self-reported beverage consumption were analyzed by Wilcoxon signed-rank test. All analyses were performed using $\mathrm{SAS}^{\circledR}$ procedures (version 8.02; SAS Institute, Cary, NC, USA), considering a p value $<0.05$ statistically significant.

The study was approved by the Ethics Committee of the University of Bonn. Written informed consent from the children's parents was obligatory for their participation.

\section{Results}

In total, 1,641 participants in the IG and 1,309 participants in the CG with anthropometrical data at both baseline and follow-up were analyzed. Participants had a mean age of 8.3 years, and $50.2 \%$ were male. Body weight status and characteristics are presented in table 1. Baseline characteristics did not differ between IG and CG regarding sex $(\mathrm{p}=0.977)$, BMI, BMI-SDS, and body weight status whereas children in the IG were slightly older at baseline and follow-up measurements than in the CG (table 1).

The incidence rate of overweight during the follow-up period of 250 days was significantly lower in the IG $(3.8 \%)$ than in the CG $(6.0 \%)$ (table 2). In contrast, the remission rate of overweight and obesity among the subgroup of overweight children did not differ significantly between IG and CG (table 2).

Cumulated water flow of the fountains in the intervention schools showed a positive linear time trend over the whole intervention period, indicating a constant consumption level (correlation coefficient $r=0.99, p<0.001$ ).

Mean self-reported water consumption increased from baseline to follow-up by 1.2 glasses/day in the IG $(p<0.001)$ whereas mean consumption of soft drinks/juices decreased by 0.2 glasses/day $(p=0.019)$. In contrast, neither water consumption nor consumption of soft drinks/juices changed sig- 
Table 2. Incidence and remission rates of overweight and obesity during the follow-up period in the intervention group (IG) and control group (CG)

\begin{tabular}{llll}
\hline & IG & CG & p value $^{\mathrm{b}}$ \\
\hline $\begin{array}{l}\text { Incidence rate, \% }(n) \\
\text { Overweight }\end{array}$ & $3.8(48)$ & $6.0(58)$ & 0.018 \\
Obesity & $7.1(20)$ & $5.2(12)$ & 0.390 \\
$\begin{array}{l}\text { Remission rate, \% }(n) \\
\quad\end{array}$ & & \\
$\begin{array}{l}\text { Overweight } \\
\text { Obesity }\end{array}$ & $16.7(47)$ & $14.4(33)$ & 0.485 \\
\hline
\end{tabular}

a According to the International Obesity Taskforce [9].

${ }^{\mathrm{b}} \mathrm{p}$ values obtained using chi-square test for group differences.

nificantly from baseline to follow-up in the CG, indicated by a difference of 0.0 glasses/day in both beverage categories ( $\mathrm{p}=$ 0.576 and $\mathrm{p}=0.670$, respectively).

\section{Discussion}

In the present analysis of a randomized controlled cluster trial, we could demonstrate that a school-based intervention solely focusing on the promotion of water consumption was effective for decreasing the incidence of overweight. Behavioral modifications by this dietary intervention for primary prevention of overweight were indicated by an improvement in the beverage consumption of the school children.

Although the number of published trials on the prevention of obesity in children has increased in recent years, there is still not enough evidence for one particular program to be effective $[2,12]$. However, the review of interventions showed that the targeting of the drinking habits seems to be a promising approach in the prevention of childhood overweight [13, 14]. Recently, 2 randomized controlled trials with interventions to reduce the consumption of soft drinks had at least partly a beneficial effect on the body weight status of children [4] and adolescents [3]. However, the trial that focused on educational measures failed to be effective in the long term [15]. The other trial applied environmental and educational interventions that were highly intensive [3] and therefore hardly feasible for primary prevention in a deprived population.

Our dietary intervention reduced the overall risk for overweight [5] and, as demonstrated here, was effective in reducing the incidence of overweight but did not affect remission of overweight or obesity. This primary prevention approach was directed to the entire population independent of body weight status. Thus, it was not expected to have a therapeutic effect in already obese or overweight children. This result supports the primary aim of the intervention to counteract the increase in prevalence of overweight in the public health context. For this purpose, the feasibility of the intervention in the school setting is of special importance. Results of the process evaluation of the intervention trial, indicating a good compliance of the teachers [5], point to a sustainable integration of the intervention in schools.

Elementary schools are an ideal setting for primary prevention since the development of health-related behaviors is determined in these age groups [14]. Furthermore, this age period is significant in the development of overweight as prevalence rates increase from $9 \%$ in preschool children to $19 \%$ in secondary school children aged 11-13 years in Germany [16], underlining the relevance of prevention in this age group. Our intervention reduced the incidence of overweight in this age group and may therefore serve as one effective measure for the prevention of overweight. In contrast, the missing effect on the remission of overweight showed that the intervention could not be used for the treatment of overweight.

As a methodological limitation, the randomization at city level has to be mentioned. Intervention and control schools were located in different cities to minimize treatment contamination but that might have resulted in regional differences between the groups. However, schools were located in districts selected by the same socio-demographic criteria resulting in similar baseline characteristics of the participants in the IG and CG.

From a public health perspective, it is of particular importance that this preventive intervention was effective among children from socially deprived neighborhoods implying a lower socio-economic background. This population group has an increased risk of overweight and obesity [16, 17] and, furthermore, a low socio-economic status seems to serve as a barrier to traditional, behavioral interventions [18, 19]. A reason for the success of our intervention even in this population group might be the environmental intervention approach that was independent from external support, e.g. of parents or study staff. Experts' suggestion that prevention programs should consider the environmental intervention approach in addition to individual behavioral changes $[2,14]$ is supported by our results.

\section{Disclosure}

The authors declared no conflict of interest. 


\section{References}

1 Lobstein T, Baur L, Uauy R; IASO International Obesity TaskForce: Obesity in children and young people: a crisis in public health. Obes Rev 2004; 5(suppl 1):4-104.

2 Summerbell CD, Waters E, Edmunds LD, Kelly S, Brown T, Campbell KJ: Interventions for preventing obesity in children. Cochrane Database Syst Rev 2005;3: CD001871.

3 Ebbeling CB, Feldman HA, Osganian SK, Chomitz VR, Ellenbogen SJ, Ludwig DS: Effects of decreasing sugar-sweetened beverage consumption on body weight in adolescents: a randomized, controlled pilot study. Pediatrics 2006;117:673-680.

4 James J, Thomas P, Cavan D, Kerr D: Preventing childhood obesity by reducing consumption of carbonated drinks: cluster randomised controlled trial. BMJ 2004; 328:1237.

5 Muckelbauer R, Libuda L, Clausen K, Reinehr T, Toschke AM, Kersting M: Promotion and provision of drinking water in schools for overweight prevention: a randomized controlled cluster trial. Pediatrics 2009;123:e661-667.

6 Stadt Dortmund, Statistik und Wahlen: Dortmunder Statistik: Bevölkerung, Jahresbericht 2005. Nr. 173. Dortmund, Stadt Dortmund, 2005.

7 Ajzen I, Madden TJ: Prediction of goal-directed behavior: attitudes, intentions, and perceived behavioral control. J Exp Soc Psychol 1986;22:453-474.

8 Kassem NO, Lee JW, Modeste NN, Johnston PK: Understanding soft drink consumption among female adolescents using the Theory of Planned Behavior. Health Educ Res 2003;18:278-291.

9 Cole TJ, Bellizzi MC, Flegal KM, Dietz WH: Establishing a standard definition for child overweight and obesity worldwide: international survey. BMJ 2000;320 1240-1243.

10 Cole TJ, Flegal KM, Nicholls D, Jackson AA: Body mass index cut offs to define thinness in children and adolescents: international survey. BMJ 2007;335:194.

11 Kromeyer-Hauschild K, Wabitsch M, Kunze D, Geller F, Geiß HC, Hesse V, von Hippel A, Jaeger U, Johnson D, Korte W, Menner K, Müller G, Müller MJ, Niemann-Pilatus A, Remer T, Schaefer F, Wittchen HU, Zabransky S, Zellner $\mathrm{K}$, Ziegler A, Hebebrand J: Percentiles of body mass index in children and adolescents evaluated from different regional German studies (in German). Monatsschr Kinderheilkd 2001;149:807-818.

12 Shaya FT, Flores D, Gbarayor CM, Wang J: School-based obesity interventions: a literature review. J Sch Health 2008;78:189-196.

13 Sharma M: School-based interventions for childhood and adolescent obesity. Obes Rev 2006;7:261-269.

14 Sharma M: International school-based interventions for preventing obesity in children. Obes Rev 2007;8:155-167.

15 James J, Thomas P, Kerr D: Preventing childhood obesity: two year follow-up results from the Christchurch obesity prevention programme in schools (CHOPPS). BMJ 2007;335:762.

16 Kurth BM, Schaffrath Rosario A: The prevalence of overweight and obese children and adolescents living in Germany. Results of the German Health Interview and Examination Survey for Children and Adolescents (KiGGS) (in German). Bundesgesundheitsbl Gesundheitsforsch Gesundheitsschutz 2007;50:736-743.

17 Wang Y, Beydoun MA: The obesity epidemic in the United States - gender, age socioeconomic, racial/ethnic, and geographic characteristics: a systematic review and meta-regression analysis. Epidemiol Rev 2007;29:6-28.

18 Müller MJ, Danielzik S, Pust S: School- and family-based interventions to prevent overweight in children. Proc Nutr Soc 2005;64:249-254.

19 Langnäse K, Masbeck I, Mast M, Müller MJ: The influence of socioeconomic status on the long-term effect of family-based obesity treatment intervention in prepubertal overweight children. Health Educ 2004;104:336-343. 